This PDF is a selection from a published volume from the National Bureau of Economic Research

Volume Title: Frontiers in Health Policy Research, Volume 5

Volume Author/Editor: Alan M. Garber, editor

Volume Publisher: MIT Press

Volume ISBN: 0-262-07234-3

Volume URL: http://www.nber.org/books/garb02-1

Conference Date: June 7, 2001

Publication Date: January 2002

Title: CMS Payments Necessary to Support HMO

Participation in Medicare Managed Care

Author: John Cawley, Michael Chernew, Catherine McLaughlin

URL: http://www.nber.org/chapters/c9856 


\title{
CMS Payments Necessary to Support HMO Participation in Medicare Managed Care
}

\author{
John Cawley, Cornell University and NBER \\ Michael Chernew, University of Michigan and NBER
}

Catherine McLaughlin, University of Michigan

\section{Executive Summary}

In recent years, many health maintenance organizations (HMOs) have exited the market for Medicare managed care; since 1998, the number of participating plans has fallen from 346 to 174 . As a result of this reduced participation by HMOs, hundreds of thousands of Medicare beneficiaries have been involuntarily disenrolled from the program at the end of each year from 1998 to 2001.

This paper estimates the Centers for Medicare and Medicaid Services (CMS) ${ }^{1}$ capitation payments that are necessary to support the participation of various numbers of HMOs in Medicare managed care per county market. This paper does not make a normative statement about how many HMOs should be supported in this program; rather, it makes a positive statement about the levels of payment necessary to support various numbers of HMOs.

The identification strategy is to observe how the number of participating HMOs varies over counties and time in response to CMS payment, while controlling for estimated costs. This paper studies the period 1993-2001 and focuses in particular on the variation in payment, independent of costs, that occurred as a result of the Balanced Budget Act of 1997, which dramatically changed the way that HMOs are paid in this program. In light of the fact that it may not be cost-effective for CMS to support HMO participation in relatively rural or unpopulated counties, the sample used in this paper is limited to the 60 percent of U.S. counties with the largest populations of Medicare beneficiaries.

The ordered probit results presented in this paper indicate that, to support one Medicare HMO in 2001 in half of the counties in the sample, CMS would have to pay $\$ 682.08$ per average enrollee per month in the marginal county. To support one Medicare HMO in 2001 in every county in the sample, CMS would need to pay $\$ 1,008.25$ per enrollee per month in the maximum-payment county. For comparison, the maximum monthly payment paid by CMS to any county in 2001 was $\$ 833.55$.

This paper finds that 79.3 percent of counties in the sample received a CMS payment in 2001 that was less than what was necessary to support a single HMO in Medicare managed care. Compared to those counties that received a payment exceeding the estimated threshold for HMO participation, these 
counties are, on average, more rural and less populated, with citizens who are less wealthy and less educated. The relative disadvantage of rural and unpopulated counties persists three years after the Balanced Budget Act of 1997, designed in part to eliminate such disparities, took effect.

\section{Introduction}

This paper studies how the equilibrium number of health maintenance organizations (HMOs) participating in county Medicare managed care markets varies with the Centers for Medicare and Medicaid Services (CMS) capitation payment. The number of HMOs participating in Medicare managed care markets is of interest for several reasons. The participation of a single HMO in a Medicare managed care market offers Medicare beneficiaries in that market an alternative to fee-forservice care. The participation of multiple HMOs in a market creates competition for enrollment, which results in greater benefits and/or lower costs for managed care enrollees. ${ }^{2}$

This paper does not take a position on how many HMOs should be supported in this program in different areas of the United States; that question is left for policy makers. Instead, this paper seeks to provide the best estimate of the levels of payment necessary to support various numbers of HMOs.

The identification strategy of this paper is to examine how the number of participating HMOs in this program varies over counties and time in response to CMS payment, controlling for estimated costs. In particular, variation in payment independent of costs occurs because of the Balanced Budget Act of 1997, which dramatically changed the way that HMOs are paid in this program.

Those eligible for Medicare Part A (Hospital Insurance) and enrolled in Medicare Part B (Supplementary Medical Insurance) may enroll in a Medicare managed care plan, if one is available. ${ }^{3}$ Figure 1.1 depicts the number of Medicare managed care enrollees from 1985 to 2001, a period during which enrollment grew from 0.44 million in 1985 to 6.35 million in 1999, before falling to 5.6 million in $2001 .{ }^{4}$ In 2001, 15 percent of all Medicare beneficiaries chose managed care. ${ }^{5}$

The continuous growth in enrollment between 1985 and 1999 masks considerable change in the number of HMO plans participating in Medicare managed care. Figure 1.2 shows that the number of participating plans rose considerably during the early and mid-1990s, but fell from 346 to 174 between 1998 and 2001. This fall in plan participation 


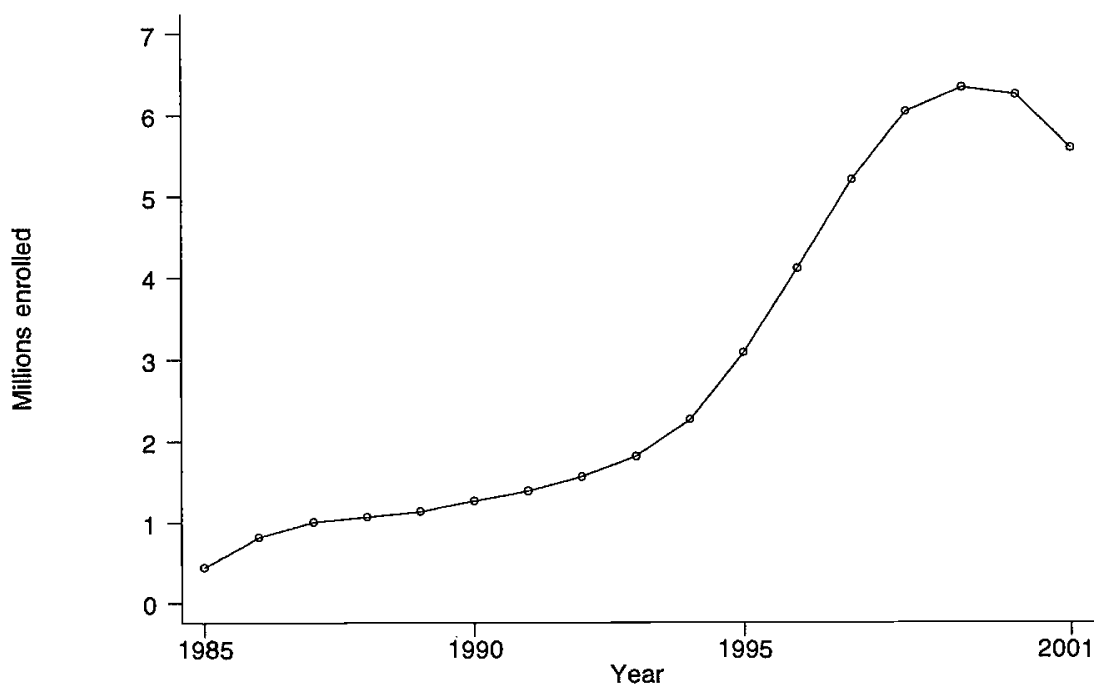

Figure 1.1

Medicare managed care enrollment

coincides with the period when the provisions of the Balanced Budget Act of 1997 were in effect.

As a result of the reduced participation of HMOs, many Medicare beneficiaries have been involuntarily disenrolled from the program. At the end of 1998, 407,000 (or 7 percent of all) Medicare HMO enrollees were involuntarily disenrolled, and 327,000 ( 5.3 percent) were involuntarily disenrolled at the end of $1999 . .^{6}$ It is estimated that 934,000 enrollees (15.1 percent) were disenrolled at the end of the year $2000 .^{7}$

Beneficiaries involuntarily disenrolled from a Medicare managed care plan are forced either to find another HMO in their county with a risk contract from Medicare or to return to traditional fee-for-service Medicare. Laschober et al. (1999) surveyed Medicare beneficiaries whose HMO had recently withdrawn from Medicare. They found that one-third experienced a decline in benefits, 39 percent reported higher monthly premiums, and one in seven lost prescription drug coverage.

It may not be cost-effective for CMS to support HMO participation in Medicare managed care in relatively rural or unpopulated counties; for this reason, the sample used in this paper is limited to the 60 percent of U.S. counties with the largest population of Medicare beneficiaries. Our estimates indicate that 79.3 percent of counties in this 


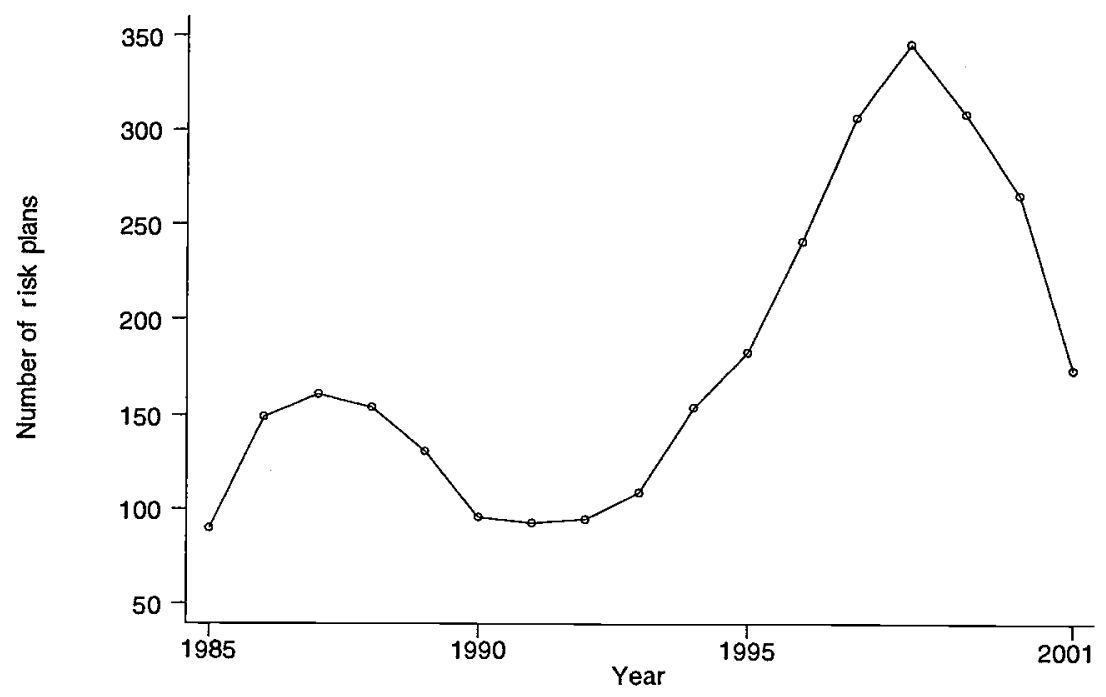

Figure 1.2

Number of Medicare managed care plans

sample received a CMS payment less than what was necessary to support a single HMO in the Medicare managed care market. In particular, CMS appears to underestimate the payment necessary to support HMOs in rural and less populous areas.

Section II of this paper outlines the methodology for examining the relationship between CMS payment rates and the extent of HMO participation. Section III describes the data used in this study; Section IV presents the results of the empirical work, and the final section presents our conclusions.

\section{Methodology}

To illustrate why higher payments may lead to a larger number of participating HMOs, suppose that the Medicare managed care market is in equilibrium, and then CMS raises the payment to HMOs while costs remain constant. The payment has been raised above the marginal cost of caring for additional Medicare beneficiaries, so HMOs will compete to increase enrollment and therefore profits. HMOs compete for enrollment by increasing benefits (and, therefore, marginal and average costs). The provision of additional benefits raises the cost curves; in particular, the average cost curve will rise to equal the new, higher payment. The provision of additional benefits makes Medicare managed 
care more attractive relative to fee-for-service Medicare; this shifts the demand curve for Medicare managed care and, as a result, the new equilibrium will be associated with a higher quantity of enrollment. Since marginal costs are rising in enrollment, the higher enrollment may be associated with a larger number of participating HMOs and cannot be associated with fewer participating HMOs.

Congress, in the Balanced Budget Act (BBA) of 1997, changed CMS's formula for setting payment levels effective in 1998. Prior to 1998, county CMS payments were set according to the 1982 Tax Equity and Fiscal Responsibility Act (TEFRA). Under TEFRA, HMOs were paid 95 percent of the projected average fee-for-service costs of Medicare beneficiaries in that county, multiplied by a risk-adjustment factor based on the enrollee's age, sex, Medicaid eligibility, institutional status, and working status.

The TEFRA payment formula was criticized for overpaying HMOs. Despite the strategy of paying HMOs 95 percent of projected average fee-for-service costs, several studies concur that it cost CMS more to enroll beneficiaries in managed care than if they had remained in fee-for-service Medicare. The reason is that enrollees in Medicare managed care have proven to be systematically healthier than fee-forservice Medicare beneficiaries. As a result, the medical expenses of the Medicare managed care enrollees were far lower than 95 percent of average fee-for-service costs. ${ }^{8}$

The TEFRA payment formula was also criticized for creating disparities in payments across counties; in particular, few HMOs entered rural counties. It was argued that tying managed care payments to local fee-for-service charges rewarded counties that were inefficient at providing fee-for-service care and counties with high reimbursements for graduate medical education, which are included in the fee-for-service costs.

Concerned about the rising cost of caring for Medicare beneficiaries, Congress passed the BBA of 1997, which created the Medicare + Choice program $(M+C)$ and changed the way that HMOs are reimbursed for risk contracts. ${ }^{9}$ Under M+C, CMS, beginning in 1998, pays HMOs the greatest of the following three rates ${ }^{10}$ :

1. A blend of an input-price adjusted national rate and an area-specific rate; however, if total projected payments exceed a budget limit, this blended rate is reduced. The blend is intended to reduce the variation in payments across counties by increasing the lowest rates and decreasing the highest rates. 
2. A minimum or "floor" payment, adjusted annually, intended to increase rates in historically lower-rate counties where Medicare managed care plans generally have not been offered.

3. A minimum increase over the previous year's payment, which is intended to protect high payment areas. For 1998, 1999, and January and February of 1999, the minimum increase over the previous year's payment was 2 percent. Since March 2001, the minimum increase is 3 percent.

Since the BBA took effect, the budget limits have typically been binding, forcing reductions in the blended rate. These reductions have been so great that only in the year 2000 did any county receive the blended payment. The BBA also affected HMO profits by increasing their administrative burdens and charging them user fees (which amounted to $\$ 95$ million in both 1998 and 1999), the proceeds of which are used to inform Medicare beneficiaries about their managed care options.

There is one final component of CMS payments to HMOs. The Balanced Budget Refinement Act of 1999 mandates that CMS, starting in the year 2000, pay bonuses of 5 percent the first year and 3 percent the second year to HMOs that offer Medicare+Choice in previously unserved counties. ${ }^{11}$

Three studies have modeled the decisions of individual HMOs to participate in the Medicare managed care market (Adamache and Rossiter 1986, Porell and Wallack 1990, and Abraham et al. 2000). Each of these studies used HMO-level data, which entails two complicated problems, neither of which is addressed by the three referenced studies.

The first problem is that, in counties with noncompetitive Medicare managed care markets, the entry decision of each firm is a function of the entry decisions of all potential participants in that market. Complicating the problem is that some potential participants are not observed because they chose not to enter.

The second problem inherent in the use of HMO-level data to study this problem is the likelihood of multiple equilibria. For example, a county may be able to support two HMOs in its Medicare managed care market, but it may be random which two HMOs participate. Bresnahan and Reiss (1991a) show that multiple equilibria occur in simultaneous-move models under very general conditions.

In this paper, we study the aggregate number of HMOs participating 
at the county level. This avoids the problems of simultaneity and multiple equilibria because we are concerned only with the number of firms that can be supported in the county, not the identities of the individual HMOs.

In our focus on the number of firms that can be supported in distinct geographic markets, our paper is similar to an earlier literature that includes Bresnahan and Reiss (1987, 1990, 1991b); Dranove, Shanley, and Simon (1992); Kronick, Goodman, Wennberg, and Wagner (1993); and Brasure, Stearns, Norton, and Ricketts (1999). ${ }^{12}$ However, we differ from this literature because our regressor of interest is not the market size but the market "price."

We follow the methodology developed in Bresnahan and Reiss (1987, $1990,1991 b$ ) in using a latent profit variable to motivate the use of an ordered probit to study the number of firms that can be supported in a geographic market. We assume that profit has an additively separable unobserved component, represented by an error term. It is assumed that the error term is normally distributed, independent across markets and independent of the regressors. We assume that all HMOs in the same market have the same unobserved profit. These assumptions permit the use of the ordered probit to estimate entry thresholds. The dependent variable is the number of HMOs participating in Medicare managed care in a county.

We estimate the latent profit function using a reduced form approach. Cameron and Trivedi (1998) conclude that when the data generating process is a continuous latent variable (in our case unobserved profits), an ordered model should be used in place of a count data regression model. ${ }^{13}$ Accordingly, we estimate our model using an ordered probit regression. The number of participating HMOs in a given county in a given year is regressed on payment and the factors that affect variable costs, market size, the probability of enrollment, and fixed costs.

Ordered probit regression will provide us with threshold values of CMS payments for HMO participation. If $\beta_{p}$ represents the ordered probit coefficient on CMS payment, $\beta$ represents the vector of all other ordered probit coefficients, and $X$ represents the set of regressors other than the CMS payment, then $P_{N}$, the minimum CMS payment needed to support the participation of $N$ HMOs, is:

$P_{N}=\frac{\lambda_{N}-X \beta}{\beta_{\rho}}$ 
where $\lambda_{N}$ is the cutoff in the ordered probit regression associated with $N$ HMOs. ${ }^{14}$ We predict that a higher CMS payment, controlling for observable factors that affect costs, will be associated with the participation of a greater number of HMOs.

\section{Data}

This section explains how we control for each component of the profit function introduced in the previous section. The data used in this paper come from two sources. CMS is the source for data on Medicare managed care enrollment, Medicare managed care contracts with HMOs, CMS payments by county, and input price indices. The second major source of data for this paper is the Area Resource File (ARF), which provides medical and demographic data at the county level. ${ }^{15}$

The unit of observation in this paper is the county. A market has traditionally been defined as a region in which a single price prevails for a homogenous good. ${ }^{16} \mathrm{By}$ this definition, counties represent distinct markets for Medicare managed care; CMS sets Medicare managed care payments on a county-by-county basis. Furthermore, CMS requires separate contracts from HMOs for each county in which they wish to offer Medicare managed care.

For the purposes of this study, a risk plan is defined as participating in a county Medicare managed care market if CMS market penetration files indicate that the plan has enrolled at least 0.5 percent of the county's Medicare-eligible residents. ${ }^{17}$ We exclude plans that have enrolled less than 0.5 percent of eligible residents because plans with such low county enrollment may not actually be operating in the county. CMS market penetration files list enrollees by their county of residence instead of the county in which they have enrolled in an $\mathrm{HMO}$; as a result, many plan enrollees are found in counties where the plan does not have a contract to operate.

The number of HMOs participating in a county, by year, is shown in table 1.1. Table 1.1 indicates that the number of counties with zero HMOs participating in Medicare managed care fell every year from 1993 to 1999, but rose from 1999 to 2001.

It may not be cost-effective for CMS to support HMO participation in Medicare managed care in relatively rural or unpopulated counties. Table 1.2 lists the percentage of counties with at least one HMO participating in Medicare managed care, by the quintile of its 1990 popu- 


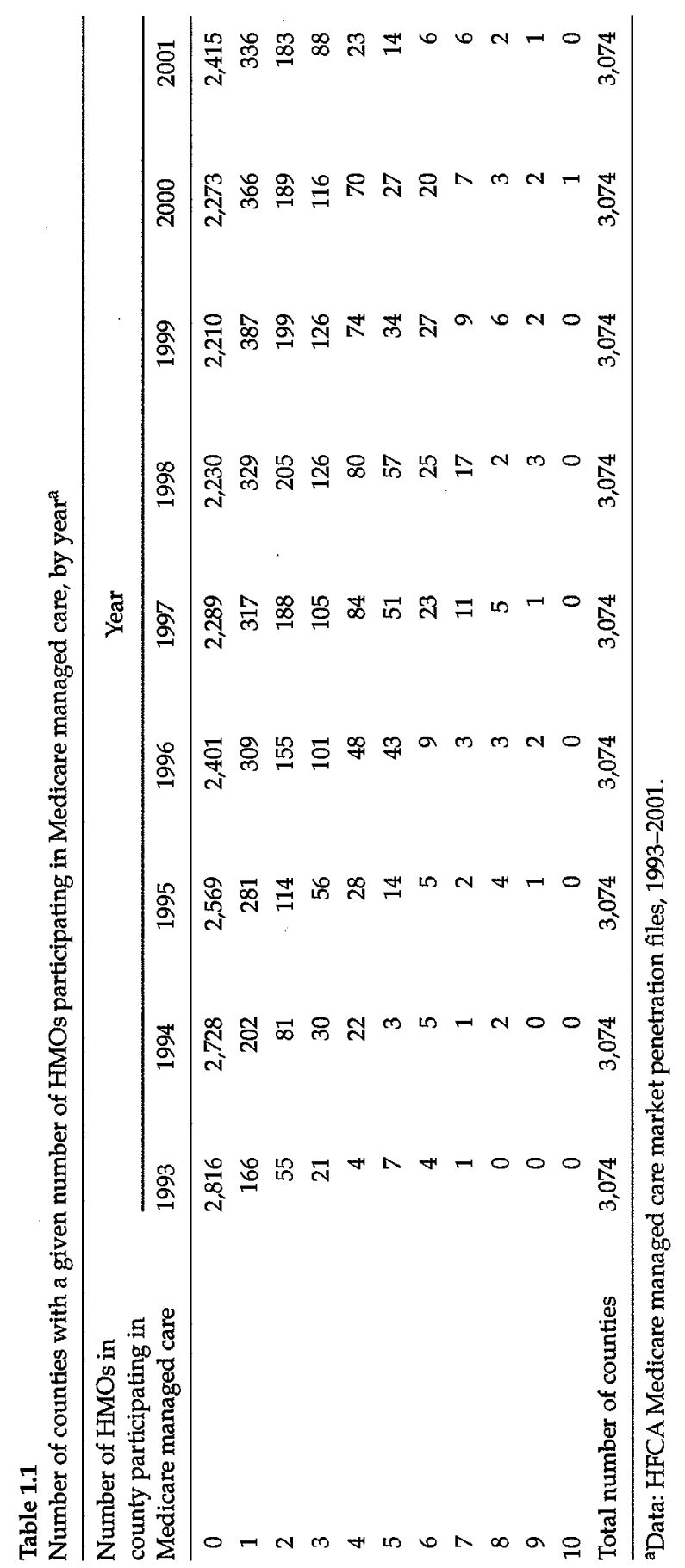


lation of Medicare beneficiaries. The table shows that counties in the fifth (most populous) quintile are several times more likely to have a participating HMO than are counties in the first quintile (least populous).

Many counties are too rural or unpopulated ever to support HMO participation, so we exclude these counties from the sample. Thus, their history of nonparticipation does not influence the payment thresholds estimated for other counties. The sample used in this paper consists of counties whose population of Medicare beneficiaries is in the top three quintiles; in other words, its 1990 Medicare population was at least 2,783. In addition, all counties in Alaska and Hawaii are excluded.

The sample contains observations of these counties for each year from 1993 to 2001. Plan-county data are aggregated to the HMO level and HMO-level data are aggregated to the county level..$^{18}$ The dependent variable used in this paper is the number of HMOs participating in a county in a given year. In ordered probit regressions, this dependent variable is top-coded at six or more. ${ }^{19}$

\section{The HMO Profit Function}

The profit function for all HMOs in a market is:

$\Pi=[P-A V C] d S-r F+\epsilon$

where $P$ is the CMS payment, $A V C$ is the average variable cost function, $d$ is the probability of enrollment in Medicare managed care of the representative Medicare eligible, $S$ is the number of Medicare eligibles, $r$ is the interest rate, $F$ is the fixed cost of entry, and $\epsilon$ represents unobserved profits. Listed below are the variables we use to proxy for each of the components of the profit function.

\section{P: Payment}

The regressor of interest is the CMS per-enrollee, per-month payment specific to the county. We enter the CMS payment directly and interact it with an indicator for the BBA regime (1998-2001), which allows the effect of the CMS payment to vary before and after the BBA of 1997 took effect. These payment variables include bonuses, paid only in 2000 and 2001, which are equal to 5 percent of the per-enrollee payment for the first year, and 3 percent of the per-enrollee payment for the second year, that an HMO operates in a previously unserved county. ${ }^{20}$ 
Table 1.2

Percentage of counties with at least one active Medicare managed care $\mathrm{HMO}$, by quintile of Medicare beneficiaries in $1990^{\mathrm{a}}$

\begin{tabular}{lrrrrr}
\hline & \multicolumn{5}{c}{ Quintile of Medicare beneficiaries in 1990} \\
\cline { 2 - 6 } Year & \multicolumn{1}{c}{1} & \multicolumn{1}{c}{2} & \multicolumn{1}{c}{3} & \multicolumn{1}{c}{4} & \multicolumn{1}{c}{5} \\
\hline 1993 & 4.7 & 2.4 & 3.9 & 7.5 & 23.5 \\
1994 & 5.4 & 3.6 & 6.0 & 10.7 & 30.6 \\
1995 & 7.6 & 4.9 & 9.8 & 15.3 & 44.6 \\
1996 & 9.8 & 7.2 & 13.0 & 22.4 & 57.2 \\
1997 & 9.9 & 9.3 & 17.1 & 27.8 & 63.7 \\
1998 & 10.9 & 10.4 & 18.9 & 31.4 & 65.8 \\
1999 & 7.6 & 12.8 & 20.3 & 33.3 & 66.4 \\
2000 & 6.5 & 12.4 & 17.1 & 31.1 & 63.4 \\
2001 & 4.2 & 9.4 & 13.8 & 22.6 & 57.2 \\
& & & & & \\
Number of counties & 615 & 615 & 615 & 615 & 614 \\
Minimum number of Medicare & & & & & \\
beneficiaries in quintile & 14 & 1,482 & 2,783 & 4,714 & 9,718 \\
Maximum number of Medicare & 1,479 & 2,781 & 4,708 & 9,680 & 877,581 \\
beneficiaries in quintile & & & & &
\end{tabular}

aData: CMS market penetration files, 1993-2001, and Area Resource File.

Although in practice the per-capita payments of CMS to HMOs are adjusted to take into account the demographic and (more recently) risk factors associated with the enrollee, we do not make these adjustments. Thus, the payment used in our empirical work represents the payment for the average enrollee. ${ }^{21}$

Summary statistics of the CMS per-enrollee monthly payments are listed in table 1.3 in nominal dollars. Table 1.3 indicates that the average CMS county monthly payment per enrollee rose each year from 1993 to 2001. The variance in the county payments rose until 1997, when the BBA was passed in part to reduce disparities in payments across counties. Since 1997, the variance in payments across counties has fallen each year. CMS payments to HMOs are constant during a calendar year; the exception to this rule is 2001, when payments were raised effective March 2001 by the Medicare, Medicaid, and State Children's Health Insurance Program (SCHIP) Benefits Improvement and Protection Act of 2000. We use the March payment rate for 2001 because the dependent variable in 2001 is also created using March data. 
Table 1.3

Summary statistics of monthly per-enrollee CMS payments, by year ${ }^{2}$

\begin{tabular}{lcccc}
\hline Year & Mean & $\begin{array}{c}\text { Standard } \\
\text { deviation }\end{array}$ & Minimum & Maximum \\
\hline 1993 & 301.86 & 55.46 & 168.15 & 598.65 \\
1994 & 314.72 & 58.29 & 171.07 & 653.44 \\
1995 & 332.43 & 62.99 & 177.32 & 678.90 \\
1996 & 372.13 & 70.58 & 207.31 & 881.35 \\
1997 & 394.78 & 76.69 & 220.92 & 767.35 \\
1998 & 417.09 & 62.99 & 367.00 & 782.70 \\
1999 & 427.33 & 62.69 & 379.84 & 798.35 \\
2000 & 449.78 & 56.85 & 401.52 & 809.28 \\
2001 (Jan.-Feb.) & 460.39 & 56.66 & 414.88 & 825.46 \\
2001 (Mar.-Dec.) & 498.82 & 41.70 & 475.00 & 833.55 \\
\hline
\end{tabular}

aFigures are in nominal dollars. The BIPA of 2000 raised payments to HMOs effective March 2001. Payments do not include bonuses for operating in previously unserved counties during 2000 and 2001.

Source: HCFA Medicare managed care historical payment files, 1993-2001.

\section{AVC: Average Variable Costs}

We do not observe the average variable costs of HMOs; we estimate these costs in the following way. We assume that average variable costs in county $c$ in year $t$, denoted $A V C_{c, t}$, have the following structure:

$A V C_{c, t}=\beta_{A} A_{c, 1991}\left(1+\frac{P_{A, t}-P_{A, 1991}}{P_{A, 1991}}+\beta_{B} B_{c, 1991}\left(1+\frac{P_{B, t}-P_{B, 1991}}{P_{B, 1991}}\right)+\beta_{x} X_{c}+\sum_{t=1994}^{2001} \beta_{t} I_{t}\right.$

where $A_{c, 1991}$ is the average Medicare Part A (Hospital Insurance) reimbursement per enrollee in county $c$ in 1991. This amount is multiplied by the percentage change in Part A costs since 1991, as measured by the CMS Hospital Input Price Index, which is represented in the equation above by $P_{A, t}{ }^{22}$ Likewise, $B_{c, 1991}$ is the average Medicare Part B (Supplementary Medical Insurance) reimbursement per enrollee in county $c$ in 1991. This amount is multiplied by the percentage change in Part B costs since 1991, as measured by the CMS Medicare Economic Index, which is represented in the equation above by $P_{B, t}{ }^{23}$ The change in costs observed over time is due to prices, not necessarily utilization. Also note that the Hospital Input Price Index and the Medicare Economic Index are nationwide indices, and therefore all of the difference across counties in costs is due to the baseline difference in costs in 1991. In the 
regression model, Part A and Part B costs will be entered separately. HMOs may be better able to control one type of costs than the other, and therefore costs in the two areas may have different effects on the likelihood that HMOs will participate.

In the average variable costs equation listed above, $X_{c}$ is a vector of county characteristics that may affect costs, specifically, the number of general practitioners in 1990, the number of registered nurses in 1990, the number of hospitals in 1993, and median rent in $1990 .{ }^{24}$ We also include as regressors population density and the percentage of the population that is urban because geographically dispersed populations may be more costly to serve. Finally, year-specific costs are captured by $I_{t}$, an indicator variable that equals 1 if the observation is for year $t$.

\section{S: Size of the Market}

Although the sample is limited to relatively populous counties, even within that group, HMOs may prefer to enter more populous counties. We control for the size of the county market using the number of Medicare beneficiaries in the county in $1990 .{ }^{25}$ We also include the percentage change in this number from 1980 to 1990 to account for the fact that HMOs may prefer to enter growing markets.

\section{F: Fixed Costs of Entry}

We control for two factors that Brown and Gold (1999) suggest affect the fixed costs of entry into the Medicare managed care market. The first is whether the HMO already operates in the commercial market in the county. This may affect the fixed costs of entering Medicare managed care for two reasons: (1) the HMO would have already sunk the costs of establishing a network of health care providers in the county (that is, there may be economies of scope to participating in multiple managed care markets in the same county), (2) CMS limits participation in the Medicare managed care market to HMOs participating in the county's commercial market. HMOs that historically participated in the commercial market of the county may face lower barriers to entering the Medicare managed care market.

We do not simply control for the number of HMOs participating in the county's commercial managed care market. Because an HMO could enter a county's commercial market for the purpose of subsequently entering its Medicare managed care market, current participation in the commercial market may be endogenous. Instead, we control for the 
number of HMOs in the county in 1980, before the TEFRA of 1982 created the modern Medicare managed care market. ${ }^{26}$ We also control for the likelihood of HMOs participating in the county commercial market using the percentage of the workforce in manufacturing or white-collar jobs in 1990. The presence of these types of workers proxies for the presence of employers likely to demand commercial managed care for its employees.

The second factor that affects the fixed cost of entering a county Medicare managed care market is whether an HMO participates in nearby counties. It may be cheaper for an HMO to enter a county adjacent to its current service area because the HMO may already be familiar with local providers and have acquired information about the local market. To proxy for the likelihood of participating in adjacent counties, we control for the total number of Medicare beneficiaries in 1990 in all adjacent counties and its percentage growth from 1980 to 1990.

\section{d: Probability That Medicare Eligibles Will Enroll in Medicare Managed Care}

It has been found repeatedly that relatively healthy Medicare beneficiaries are the most likely to enroll in managed care. ${ }^{27}$ To capture cross-county differences in the proportion of healthy beneficiaries (and therefore demand for Medicare managed care), we control for per capita income, the poverty rate among the county's elderly, the percentage of adults with a high school diploma, and the percentage of adults with a college degree. ${ }^{28}$ Each of these variables was measured in 1990.

Summary statistics for the sample used in this paper appear in table 1.4 .

We acknowledge that characteristics of the individual HMOs participating in the market may affect variable or fixed costs, or the triggers at which the HMO will enter or exit. For example, certain model types may be more efficient at providing care and the exit trigger may be lower for nonprofit than for for-profit HMOs. We ignore the characteristics of the individual participating HMOs for two reasons. First, these characteristics are endogenous. An HMO may change its model type or profit status to suit the characteristics of the markets in which it participates. Second, as mentioned earlier, HMO entry into Medicare managed care is an example of a multiple-agent discrete-move game. It is likely that multiple equilibria exist and that the number of firms participating is determined, but the identity of the individual HMOs that participate is to some extent random. 


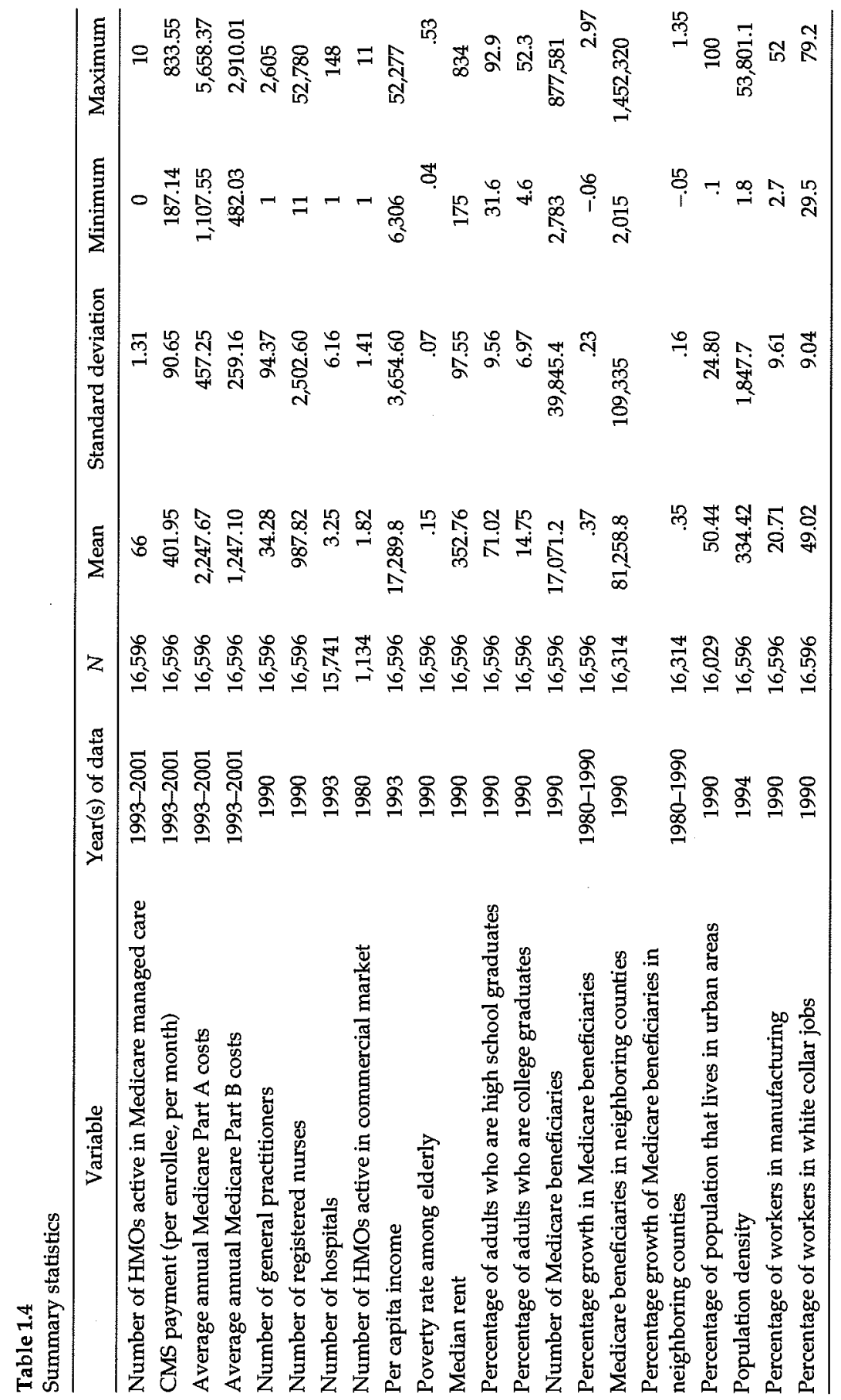




\section{Empirical Results}

The results of the ordered probit regression of the number of HMOs participating in Medicare managed care at the county level are presented in table 1.5. In all the results reported in this paper, standard errors are cluster-corrected to account for the dependence in errors within each county over time. The coefficients on CMS payment and CMS payment interacted with the BBA regime are positive and statistically significant at the 1 percent level, which is consistent with our hypothesis that, controlling for costs, a higher payment is associated with the participation of more HMOs.

As described in Section $\Pi$, the coefficients presented in table 1.5 can be used to calculate the CMS payments necessary to support a given number of HMOs in the market. Each county has unique thresholds needed to support given numbers of HMOs in this program. Rather than report the thresholds associated with over 2,000 counties, table 1.6 lists the payment thresholds associated with counties at the 25 th, 50th, 75 th, and 100 th percentiles for payment threshold.

Table 1.6 indicates that to support a single HMO in the median county in the sample, it is necessary for CMS to pay $\$ 682.08$ per average enrollee per month in the median county. To support a single HMO in every county of the sample, CMS would have to pay $\$ 1,008.25$ per average enrollee per month in the maximum-payment county.

Table 1.6 also lists the CMS payment thresholds necessary to support multiple HMOs in county Medicare managed care markets. CMS may desire multiple HMOs in each market because the competition between the HMOs for market share leads to lower out-of-pocket costs and additional benefits for enrollees. Table 1.6 suggests that, conditional on two HMOs already participating, CMS must pay roughly $\$ 115$ more per enrollee per month to support each additional Medicare HMO.

Although we report our estimated thresholds to the cent, we do not claim absolute precision about the estimates. The exact threshold is determined in part by assumptions, such as the functional form of regression. The standard errors, which appear in parentheses below the thresholds in table 1.6, in some cases imply large confidence intervals. Derivation of standard errors for the thresholds is difficult because the thresholds are nonlinear functions of several random variables. Accordingly, we calculate bootstrap standard errors. Specifically, bootstrap samples of size equal to the overall sample are formed by 
Table 1.5

Ordered probit regression of number of HMOs in county on county characteristics

\begin{tabular}{|c|c|c|}
\hline Variable & Coefficient $t^{\mathrm{a}}$ & Z Score ${ }^{b}$ \\
\hline \multicolumn{3}{|l|}{ Payment } \\
\hline CMS payment & .0034 & 4.04 \\
\hline CMS payment * indicator for $1998-2001$ & .0016 & 4.61 \\
\hline \multicolumn{3}{|l|}{ Indicator variables for year } \\
\hline 1994 & .2402 & 8.57 \\
\hline 1995 & .5610 & 13.23 \\
\hline 1996 & .8232 & 12.25 \\
\hline 1997 & 1.0187 & 12.52 \\
\hline 1998 & .3526 & 2.05 \\
\hline 1999 & .2861 & 1.62 \\
\hline 2000 & .0050 & 0.03 \\
\hline 2001 & -.5497 & -2.45 \\
\hline
\end{tabular}

Variables affecting average variable costs

\begin{tabular}{lcr}
\hline Average Medicare Part A costs & -.00002 & -0.88 \\
Average Medicare Part B costs & .0002 & 1.41 \\
Number of general practitioners & .0030 & 3.09 \\
Number of registered nurses & -.0002 & -2.87 \\
Number of hospitals & .0067 & 0.65 \\
Median rent & .0034 & 6.66 \\
Population density & -.00002 & -1.85 \\
Percentage of population in urban areas & .0013 & 0.84 \\
Measures of the size of the market & & \\
\hline Number of Medicare beneficiaries & .000007 & 2.36 \\
Percentage of growth in Medicare beneficiaries & .3024 & 2.07 \\
Variables affecting fixed costs of entry & & \\
\hline Number of HMOs in county in 1980 & -.0202 & -0.18 \\
Percentage of workforce in manufacturing & -.0042 & -1.12 \\
Percentage of workforce who are white collar & .0276 & 3.12 \\
Number of Medicare beneficiaries in all adjacent counties & .000003 & 7.35 \\
Percentage growth in Medicare beneficiaries in all & & \\
adjacent counties & .4744 & 2.24 \\
Variables affecting the probability of enrollment & & \\
\hline Per capita income & -.00002 & -1.90 \\
Poverty rate among elderly & -1.1877 & -1.55 \\
Percentage of adults with high school diploma & .0223 & 3.36 \\
Percentage of adults with college degree & -.0400 & -4.18 \\
Number of observations & 16,596 & \\
Log likelihood & $-12,618.9$ & \\
\hline
\end{tabular}

${ }^{a}$ Coefficients on indicator variables for missing values are omitted.

${ }^{b} \mathrm{Z}$ scores reflected cluster-corrections of standard errors by county. 


\section{Table 1.6}

Estimated monthly payments necessary to support given numbers of $\mathrm{HMOs}$ in Medicare managed care per county in the year $2001^{\mathrm{a}, \mathrm{b}}$

\begin{tabular}{lcccc}
\hline \multirow{2}{*}{$\begin{array}{c}\text { Desired number of } \\
\text { HMOs / county }\end{array}$} & \multicolumn{3}{c}{ Monthly CMS payment necessary (\$) } \\
\cline { 2 - 5 } & 25th percentile & Median & 75th percentile & Maximum \\
\hline 1 & 568.75 & 682.08 & 764.21 & $1,008.25$ \\
& $(19.23)$ & $(55.70)$ & $(85.61)$ & $(147.02)$ \\
2 & 710.18 & 823.51 & 905.64 & $1,149.68$ \\
& $(59.26)$ & $(99.33)$ & $(129.38)$ & $(189.77)$ \\
3 & 832.03 & 945.36 & $1,027.49$ & $1,271.53$ \\
& $(96.42)$ & $(136.95)$ & $(167.03)$ & $(226.79)$ \\
4 & 947.45 & $1,060.78$ & $1,142.90$ & $1,386.95$ \\
& $(132.63)$ & $(173.36)$ & $(203.46)$ & $(262.99)$ \\
5 & $1,053.46$ & $1,166.79$ & $1,248.91$ & $1,492.96$ \\
& $(162.61)$ & $(203.38)$ & $(233.48)$ & $(292.95)$ \\
6 or more & $1,163.66$ & $1,277.00$ & $1,359.12$ & $1,603.17$ \\
& $(194.46)$ & $(235.47)$ & $(265.47)$ & $(324.60)$ \\
\hline
\end{tabular}

${ }^{a}$ Calculated using coefficients reported in table 1.5.

bSample consists of counties with Medicare population in top three quintiles. Bootstrap standard errors appear in parentheses. Payments calculated using ordered probit coefficients.

randomly selecting, with replacement from the overall sample, all observations of a particular county. The standard errors are calculated from the variance observed in the thresholds calculated using the bootstrapped samples. We follow the recommendation of Efron and Tibshirani (1993) and conduct 200 replications to estimate standard errors.

Table 1.7 compares the mean characteristics of two groups of counties: those in which CMS payments in the year 2001 were more than the estimated payment necessary for one HMO to participate in the county, and those in which CMS payments were less than that threshold. The table also lists the difference in means and the $t$ statistic associated with the test of the hypothesis that the means are equal across the two groups of counties.

In the year 2001, 381 counties in the sample were assigned CMS payments that exceeded the estimated payment necessary to support one $\mathrm{HMO}$, while 1,463 counties were assigned payments less than the single-HMO threshold. Table 1.7 indicates that counties assigned payments greater than the estimated single-HMO threshold have both higher CMS payments and higher Part A and B Medicare costs than the 


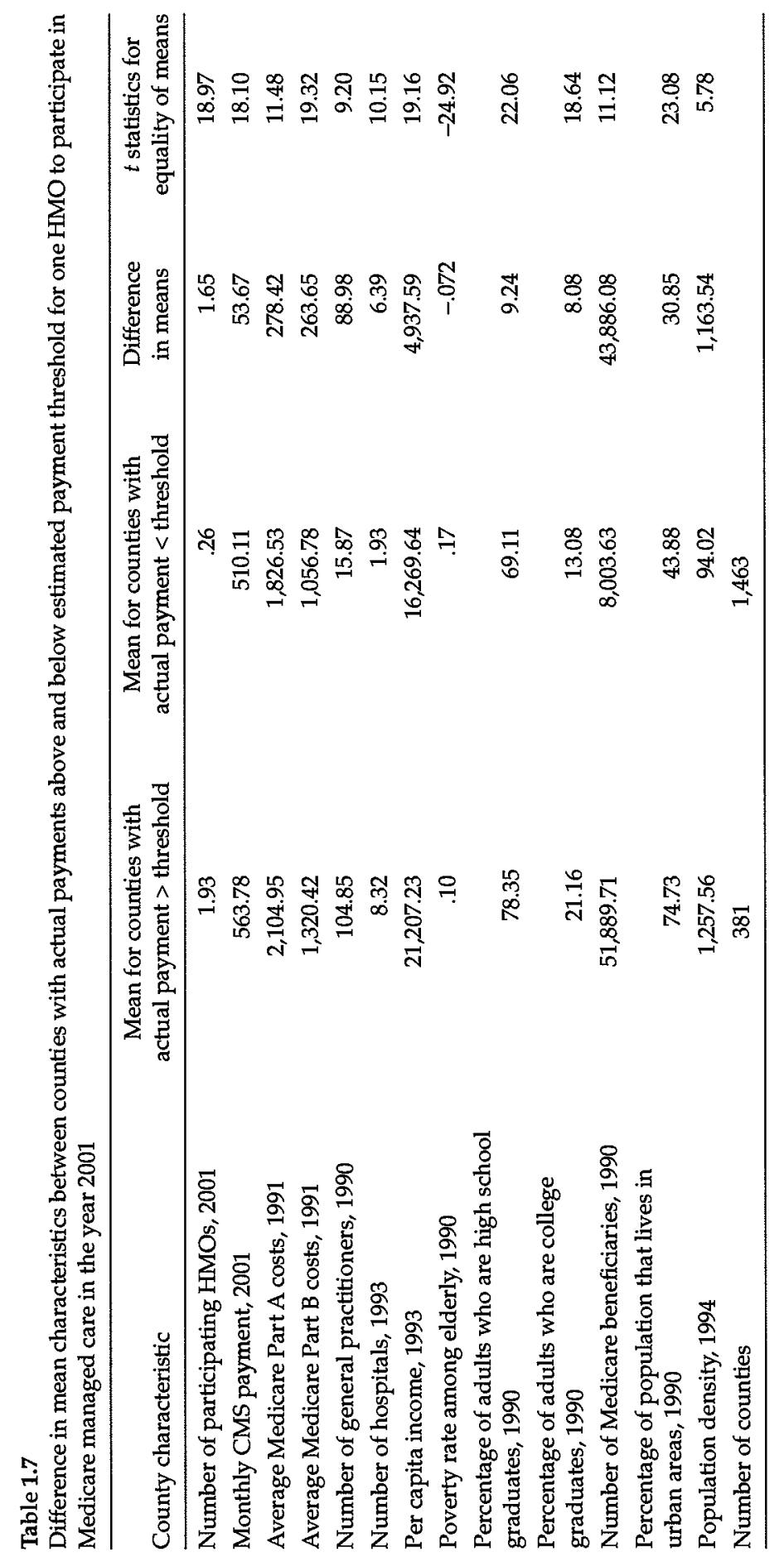


counties assigned payments less than the threshold. In addition, the counties with above-threshold payments have many more hospitals and general practitioners and, in general, have better educated and wealthier populations. Each of these differences is statistically significant at the 1 percent significance level. Perhaps the most dramatic difference is in the size of the Medicare population: counties assigned payments greater than the estimated single-HMO threshold have on average a Medicare beneficiary population of almost 51,900, whereas counties assigned payments less than that threshold have on average a Medicare bene- ficiary population of only about 8,000 .

If a below-threshold current payment can be interpreted as an underestimate by CMS of costs in that county, then our results suggest that CMS tends to underestimate the costs of HMO participation in sparsely populated counties. Several studies noted that, under the TEFRA payment scheme that was used prior to 1998, rural counties were particularly unlikely to be served by HMOs. ${ }^{29}$ Passage of the BBA was intended to eliminate such disparities by raising payments more quickly in low-payment than in high-payment counties. We find that even three years after the BBA took effect, counties with CMS payment insufficient to support HMO participation tend to be far less populous than counties that receive what we estimate to be sufficient payment. This pattern is found in a sample that includes only those counties with a Medicare population large enough to be considered viable for $\mathrm{HMO}$ activity in this program.

\section{Conclusion}

At the end of 1998, 1999, and 2000, HMO exits from Medicare managed care markets resulted in the involuntary disenrollment of hundreds of thousands of elderly and disabled Americans from a program that was intended to generate additional benefits for beneficiaries and savings for Medicare. This paper estimates the CMS payments necessary to support the participation in Medicare managed care of a given number of HMOs per county market. Ordered probit estimates suggest that, to support one Medicare HMO in half of U.S. counties in our sample in 2001, CMS would have to pay $\$ 682.08$ per average enrollee per month in the marginal county. To support one Medicare HMO in every county in the sample in the year 2001, CMS would need to pay $\$ 1,008.25$ per enrollee per month in the maxi- 
mum-payment county. In the year 2001, actual CMS payments range from $\$ 475.00$ to $\$ 833.55$.

Competition among Medicare HMOs generates additional services at lower cost for enrollees. If CMS desires multiple HMOs to participate in county markets, our estimates suggest that even greater payments are required. If two HMOs are already participating, roughly an extra $\$ 115$ per enrollee per month is necessary to support each additional Medicare HMO.

We find that 79.3 percent of all counties in our sample received less than the estimated amount necessary to support an HMO in this market. Compared to counties that received more than the estimated threshold for HMO participation, the counties receiving an insufficient payment are on average more rural and are less populated with citizens who are wealthy and educated. The relative disadvantage of rural and unpopulated counties persists three years after the BBA 1997, which was designed to eliminate such disparities, took effect. This pattern is found in a sample that includes only those counties with a Medicare population large enough to be considered viable for $\mathrm{HMO}$ activity in this program.

\section{Notes}

We thank the following people for their helpful comments and suggestions: Scott Adams, David Colby, Julie Cullen, Rachel Dunifon, Alan Garber, Hanns Kuttner, David Meltzer, Katie Merrell, and participants at the NBER Frontiers in Health Policy Research Conference held June 7, 2001, in Bethesda, Maryland. We thank Phil DeCicca for his expert research assistance. Please email comments to jhc38@cornell.edu.

1. In 2001, the Health Care Financing Administration was renamed the Center for Medicare and Medicaid Services. For the sake of consistency, the agency is referred to throughout this paper as CMS.

2. HMOs competing for market share in the Medicare managed care market tend to lower their premia or offer additional benefits to enrollees; see Physician Payment Review Commission (1996) and General Accounting Office Report 97-133 (1997c).

3. Medicare beneficiaries may enroll only in those HMOs with a risk contract from CMS to serve the beneficiary's county of residence. Medicare beneficiaries suffering from end-stage renal disease are not eligible for Medicare managed care.

4. CMS Medicare Managed Care Contract Reports are the source of the data shown in figures 1.1 and 1.2. The data for each year are from the December report, except the data for 2001, which are from the January report.

5. Health Care Financing Administration Medicare Managed Care January Contract Report (2001). 


\section{Laschober et al. (1999).}

\section{Health Care Financing Administration (2000b).}

8. Studies of data prior to 1990 find that the health care costs of Medicare managed care enrollees were $20-42$ percent lower than fee-for-service beneficiaries with the same demographic characteristics. Studies of post-1990 data find that the health care costs of Medicare managed care enrollees were 12-37 percent lower than comparable fee-for-service Medicare beneficiaries; see the review in General Accounting Office Report 97-16 (1997b). This has held true even after passage of the BBA. It is estimated that in 1998 HMOs were paid on average $\$ 1,000$ more per enrollee than CMS would have paid had the enrollees remained in fee-for-service Medicare; see General Accounting Office Report 00-161 (2000). This favorable selection occurred even though HMOs are prohibited by law from selecting enrollees on the basis of health status.

9. Some provisions of the BBA were amended by the Balanced Budget Refinement Act of 1999 and the Medicare, Medicaid, and SCHIP Benefits Improvement and Protection Act of 2000 .

10. In addition, the BBA requires CMS to adjust payments by the health status of plan enrollees. The risk adjustment will be phased in; payments in 2001 are 10 percent risk adjusted and 90 percent adjusted only for demographic factors. The full amount of the payment will be risk-adjusted by 2004 .

11. The bonus is paid to the first HMO to enter a previously unserved county; if several HMOs enter on the same date, they each receive the bonus.

12. These papers did not study the market for Medicare managed care. Bresnahan and Reiss (1987, 1990, 1991b) studied markets for retail and professional service industries; Dranove, Shanley, and Simon (1992) studied hospitals; and Brasure, Stearns, Norton, and Ricketts (1999) studied physicians. Using a different methodology, Kronick, Goodman, Wennberg, and Wagner (1993) estimated the metropolitan area population necessary to support three HMOs in the commercial managed care market.

13. Cameron and Trivedi (1998), p. 86.

14. If the dependent variable in an ordered probit regression has $M$ categories, the cutoffs represent fitted values above which the model predicts that the dependent variable will equal $m$ for $m=1, \ldots, M$.

15. The Area Resource File (ARF) is a compilation of data from various sources. Unless otherwise noted, the original source of data taken from the ARF is the 1990 Census of Population and Housing.

16. See, for example, Marshall (1920), Book V, Chapter 1.

17. The enrollment data used to determine HMO participation is that for December for 1993-1997 and 2000, October for 1998-1999, and March in 2001. December reports are not used for 1998 and 1999 because the figures listed in those December reports are actually from the following January.

18. A plan is a uniform set of benefits and premiums. Each HMO may offer multiple plans. In our data, we find only thirty-seven counties in which a single HMO offers two plans.

19. We top-code the dependent variable because it can be difficult to estimate an ordered probit for values of the dependent variable that appear rarely in the data. 
20. We determine whether each county is eligible for a bonus by checking the Medicare Managed Care geographic service area reports to see whether any HMO had a risk contract with CMS to serve the county the previous calendar year.

21. Demographic and risk adjustments are uniform across counties.

22. The Hospital Input Price Index tracks changes in the prices of hospital inputs such as wages, salaries, benefits, professional fees, utilities, liability insurance, pharmaceuticals, food, chemicals, medical instruments, photographic supplies, rubber and plastics, paper products, apparel, machinery and equipment, and other inputs.

23. The Medicare Economic Index tracks changes in the prices of inputs to physician-provided care such as physician compensation, nonphysician compensation, office expenses, medical materials and supplies, liability insurance, medical equipment, and other expenses.

24. The source of the data on the number of doctors is the American Medical Association Physician Masterfile, and that for the number of hospitals is the American Hospital Association Survey of Hospitals.

25. The number of Medicare beneficiaries includes both elderly and disabled beneficiaries (both are eligible for managed care). In 1998, the elderly represented 87.06 percent of all Medicare beneficiaries.

26. The source of the data on commercial HMO historic participation is the National HMO Census of Prepaid Plans.

27. Chapter 15 of Physician Payment Review Commission (1996) summarizes the literature that finds Medicare beneficiaries who enroll in managed care, compared to those who remain in fee-for-service Medicare, tend to have had lower utilization and Medicare costs in the preceding few years. See also General Accounting Office Report 97-160 (1997a). A similar difference in prior utilization characterizes those who enroll in commercial managed care plans; see the summary in Glied (2000). Possible reasons that the relatively healthy are more likely to enroll in managed care are that they are less likely to have an established health care provider and that they may be less averse to the risk that HMOs may deny them certain treatments.

28. We assume that the per-capita income and education of Medicare beneficiaries track those of the entire adult population in the county. The source of data on the poverty rate among the elderly is the Small Area Income Poverty estimates from the Bureau of the Census and that for per-capita income is the U.S. Department of Commerce.

29. See, for example, Serrato, Brown, and Bergeron (1995).

\section{References}

Abraham, Jean, Ashish Arora, Martin Gaynor, and Douglas Wholey (2000). "Enter at Your Own Risk: HMO Participation and Enrollment in the Medicare Risk Market," Economic Inquiry 38(3):385-401.

Adamache, Killard W., and Louis F. Rossiter (1986). "The Entry of HMOs into the Medicare Market: Implications for TEFRA's Mandate," Inquiry, 23:349-364.

Brasure, Michelle, Sally C. Stearns, Edward C. Norton, and Thomas Ricketts (1999). "Competitive Behavior in Local Physician Markets," Medical Care Research and Review 56(4):395-414. 
Bresnahan, Timothy F, and Peter C. Reiss (1987). "Do Entry Conditions Vary Across Markets?" Brookings Papers on Economic Activity, \#3:833-881.

Bresnahan, Timothy F., and Peter C. Reiss (1990). "Entry in Monopoly Markets," Review of Economic Studies 57(4):531-553.

Bresnahan, Timothy F., and Peter C. Reiss (1991a). "Empirical Models of Discrete Games," Journal of Econometrics 48(1/2):57-81.

Bresnahan, Timothy F., and Peter C. Reiss (1991b). "Entry and Competition in Concentrated Markets," Journal of Political Economy 99(5):977-1009.

Brown, Randall S., and Marsha R. Gold (1999). "What Drives Medicare Managed Care Growth?" Health Affairs, 18(6):140-149.

Cameron, A. Colin, and Pravin K. Trivedi (1998). Regression Analysis of Count Data. NY: Cambridge University Press.

Dranove, David, Mark Shanley, and Carol Simon (1992). "Is Hospital Competition Wasteful?" RAND Journal of Economics 23(2):247-262.

Efron, Bradley, and Robert J. Tibshirani (1993). An Introduction to the Bootstrap. NY: Chapman \& Hall.

General Accounting Office (1997a). "Medicare: Fewer and Lower Cost Beneficiaries with Chronic Conditions Enroll in HMOs," Report 97-160. Washington, D.C.: United States General Accounting Office.

General Accounting Office (1997b). "Medicare HMOs: CMS Can Promptly Eliminate Hundreds of Millions in Excess Payments," Report 97-16. Washington, D.C.: United States General Accounting Office.

General Accounting Office (1997c). "Medicare Managed Care: HMO Rates, Other Factors Create Uneven Availability of Benefits," Report 97-113. Washington, D.C.: United States General Accounting Office.

General Accounting Office (2000). "Medicare+Choice: Payments Exceed Cost of Fee-for-Service Benefits, Adding Billions to Spending," Report 00-161. Washington, D.C.: United States General Accounting Office.

Glied, Sherry (2000). "Managed Care," in Anthony J. Culyer and Joseph P. Newhouse, eds., Handbook of Health Economics, Volume 1A. NY: Elsevier/North-Holland.

Health Care Financing Administration (2000). "Protecting Medicare Beneficiaries After Medicare+Choice Organizations Withdraw," CMS Fact Sheet. Washington, D.C.: Department of Health and Human Services.

Health Care Financing Administration (1990-2001). Medicare Managed Care Contract Reports. Washington, D.C.: Department of Health and Human Services.

Kronick, Richard, David C. Goodman, John Wennberg, and Edward Wagner (1993). "The Demographic Limitations of Managed Competition," New England Journal of Medicine, 328(2):148-152.

Laschober, Mary A., Patricia Neuman, Michelle S. Kitchman, Laura Meyer, and Kathryn M. Langwell (1999). "Medicare HMO Withdrawals: What Happens to Beneficiaries?" Health Affairs, 18(6):150-157. 
Marshall, Alfred (1920). Principles of Economics, Eighth Edition. Philadelphia, PA: Porcupine Press.

Physician Payment Review Commission (1996). Annual Report to Congress. Washington, D.C.: Physician Payment Review Commission.

Porell, Frank W., and Stanley S. Wallack (1990). "Medicare Risk Contracting: Determinants of Market Entry," Health Care Financing Review, 12(2):75-85.

Serrato, Carl, Randall S. Brown, and Jeanette Bergeron (1995). "Why Do So Few HMOs Offer Medicare Risk Plans in Rural Areas?" Health Care Financing Review, 17(1):85-97. 
